\title{
Online Playgrounds and Transnational Gaming Cultures
}

\author{
JEFFREY WIMMER \\ UNIVERSITY OF TECHNOLOGY ILMENAU, GERMANY
}

\author{
Larissa Hjorth and Dean Chan (eds) \\ Gaming Cultures and Place in Asia-Pacific
}

Routledge, New York, 2009

ISBN 9780415996273

RRP $£ 85$ (hb)

Digital games as a key medium of our society are a common topic of the social discourse, although the discussion is mainly narrowed down to aspects of the protection of minors, the potential addictiveness of games and their level of violence. Parallel to this, cross-national and cross-disciplinary research on digital games-so-called game studies, originating in the 1990s-has evolved into an institutionalised scientific discipline with many corresponding conferences, an international research association (Digra) and a number of peer-reviewed journals. After this promising start, game studies as a quickly developed field of research meets a double challenge because of the specific characteristics of their object of research: its interactivity and the different modes of action based on it. On the one hand, do efficient definitions of terms, theories and methods already exist? On the other, is the greater urgency to develop new theoretical and methodical frameworks for research and analysis? 
From the perspective of communication and media studies, gaming constitutes an incredibly complex phenomenon of mediated communication that is based on a global, multilayer and mostly only virtual game culture. Furthermore, digital games, especially the many online playgrounds, are considered as communication media that we use to connect with society. Consequently, the following question arises: what social, cultural and thus meaningful significance do digital games possess and how is this induced? An observation of the culture of gaming, especially in terms of the quality of experiences and everyday usage, will allow us to better understand these complex processes, although we may still know very little about the highly diverse digital game cultures.

This edited collection presents a welcome selection of different theoretical and methodological approaches to the phenomenon of game cultures, especially in the region of Asia-Pacific. The editors' main objective is to first situate the depth and variety of game cultures (which are broadly defined to include games, game play and gaming communities) in this specific geographical region and then to consider how these gaming cultures in turn provide a lens to view and examine salient geopolitical and socio-cultural developments within this region. (1) More specifically, the editors want to map the sociotechnological, sociocultural, technonationalist and economic dimensions required to fully understand gaming as both a new media and social phenomenon. (5) Game cultures, as a prevailing manifestation of media culture, possess the power to 'playfully' overcome any communicational, medial or physical boundaries. Larissa Hjorth and Dean Chan exemplify this crossing of borders with (new) continuities and disjunctures, where Seoul (South Korea) and Tokyo (Japan) constitute gravitational centres of mobility and games in equal measure.

The editors and contributors tend to merely provide a systematic overview. The book's most significant feature is the impeccable description of the many specific characteristics of certain computer games and their particular ways of appropriation, such as the gaming centres of South Korea (PC Bang) or the fan culture of Pokèmon. Those who expect a critical appraisal of the already quite extensive and increasingly relevant studies of game cultures will be slightly disappointed. Nevertheless, it is not only the breadth of this book and its numerous chapters that account for its impact and relevance as a resource for students, 
lecturers, media producers, representatives of the gaming industry and civilians with general interest in the scientific discipline of game studies and, more specifically, in the socio-cultural differences and contextual specificities of the Asia Pacific Region that become apparent in game cultures. (4) The authors provide new impulses as well as alternative theoretical reference frameworks for the debate. The number of issues covered is substantial and here can only be described rudimentarily.

The book is divided into four parts, while the individual chapters stand alone without much connection to each other. The first part covers the industry behind game cultures with well-chosen case studies for three nations: South Korea by Dal Yong Jin and Florence Chee, Australia by Sam Hinton and Singapore by Peichi Chung. All three analyses clearly indicate the mutual influence of cultural and economic contexts of gaming experiences.

The second part addresses the 'localities' of the different game cultures. Based on Doreen Massey's groundbreaking approach, this refers to the specific history and context of (gaming) locations. Examples are the transnational appropriation of Japanese games in Hong Kong (Benjamin Wai-Ming Ng), the major impact of gaming centers ( $P C$ Bang) in South Korea (Jun-Sok Huhh) and the specificities of LAN-gaming (local area networks) in Australia and New Zealand (Melanie Swalwell).

The third part is confusingly titled 'Genres and New Rubrics'. It approaches gaming genres only remotely, rather dealing with new everyday gaming practices in the context of specific game cultures that refer to 'politics, storytelling and experiences of embodiment'. (137) The emerging practices of playfully becoming acquainted with the possibilities of digital media are most tangible here. Dean Chan studies the in-game protests in Chinese Online games that could be seen as nascent public collective action. Additional case studies illustrate the appropriation and consumption of Pokèmon (David Surman) and StarCraft (Christian McCrea). Aside from the popular gaming genres, other highly interesting gaming phenomena that are often neglected in research are also portrayed, like the usage of a game engine to represent Aboriginal cultural heritage (Theodor W. Wyeld et al.) or the playful adoption to mobile phones through their gaming applications (Ingrid Richardson). 
The final part of the book is explicitly dedicated to players and virtual communities. The case studies of guild-organised computer games in Taiwan (Holin Lin and Chuen-Tasi Sun), the phenomenon of cosplay (costume play) in Australia (Larissa Hjorth) or the situation of female computer players in Seoul (Larissa Hjorth et al.) show vivid evidence of the dialectics of game cultures-especially new forms of engagement and simultaneously new forms of exploitation.

Aspects of this book that attract criticism are mostly those common to the general format of edited volumes. Not all relevant and significant perspectives within and outside the game studies are adequately incorporated. Also, a self-critical assessment of the applied theories and empirical quality of the particular studies would have been appropriate. This is apparent in the particular use of the term 'game culture' and the lack of a continuous definition that is properly explained. Documentation of the cited computer games and internet addresses in an appendix and the addition of a glossary would emphasise its character. An extremely positive aspect, however, is that this collection does not merely portray an adaptation of the current Anglo-American and Scandinavian research, even though these authors strongly dominate the academic discussion.

Jeffrey Wimmer is assistant professor at the Ilmenau University of Technology, Germany. He gained his PhD 2006 on the topic of the modern mediated public sphere. He has carried out several empirical studies and published widely on the link between new media, audience and public spheres. He is also chair of the ECREAsection 'communication and democracy'. 